\title{
Um Tiago Veiga Líquido
}

\section{A Liquid Tiago Veiga}

José Vieira

Centro de Literatura Portuguesa, Faculdade de Letras da Universidade de Coimbra, Coimbra / Portugal

jose_e_c_vieira@hotmail.com

Resumo: O presente texto tem como objetivo demonstrar a liquidez de Tiago Veiga, de acordo com os preceitos de Zygmunt Bauman. A partir da análise de Tiago Veiga. Uma Biografia, daremos conta do modo como o poeta minhotoque está para lá da criação heteronímica pessoana, utiliza as imagens do turista e do vagabundo como forma de existência literária. A viagem terá um lugar primacial, na medida em que a identidade do sujeito, múltipla, líquida e fragmentada, tem na prevenção da fixação o seu móbil último. A liquidez presente nas viagens e no estar em constante movimento é, portanto, uma nova característica a acrescentar à criação heteronímica.

Palavras-chave: heteronímia; Zygmunt Bauman; turista; vagabundo; viagem.

Abstract: The present text aims to demonstrate the liquidity of Tiago Veiga, according to the precepts of Zygmunt Bauman. Through the analysis of Tiago Veiga. Uma Biografia, we will account on how the Minho's poet is beyond the "Pessoan" heteronomy creation, utilizing images from the tourist and the vagabond as means of literary existence. The journey will have a primartial place, in a way that the subject's identity, multiple, liquid and fragmented, has in order to prevent the fixation of the objective. The presence of this liquidity in these journeys 
and the state of constant movement is in fact a new characteristic to add to the heteronimic creation.

Keywords: heteronomy; Zygmunt Bauman; tourist; vagabond; journey.

Recebido em 30 de maio de 2018

Aprovado em 17 de setembro de 2018

A 18 de agosto de 1988, no suplemento "Cultura" do extinto jornal Tempo, é redigido um texto que dá conta do falecimento de um poeta desconhecido, de nome Tiago Veiga.

Segundo a peça, Veiga faleceu "serenamente" aos 88 anos de idade. De seguida, a notícia avança para uma pequena nota biobibliográfica, dando conta de várias informações acerca do poeta, desde a sua aclamação, na juventude, por Fernando Pessoa, "como o Super-Camões" (CLÁUDIO, 1988), até às suas inúmeras viagens pelo mundo que o levaram a travar conhecimento com grandes figuras da intelligentsia portuguesa e europeia, como Teixeira de Pascoaes, EzraPound, Jean Cocteau, Benedetto Croce, Eliot, entre tantos outros.

Com a notícia da sua morte, o leitor e o público não só ficam a saber da existência de Tiago Veiga, como também se apercebem da grande extensão da sua obra e da importância das suas relações pessoais e da sua longa vida. Outro pormenor que interessa realçar é o facto de toda a obra de Veiga se encontrar inédita, assim como a quase inexistência de correspondência, uma vez que os destinatários do poeta "sempre assumiam o compromisso-de-honra de destruir, pelo fogo, imediatamente à primeira leitura, as missivas que dele recebessem" (CLÁUDIO, 1988).

Tiago Veiga surge, deste modo, envolto num mistério que o remete tanto para o anonimato como para a grandeza da solidão e do desconhecido. Mário Cláudio apresenta-nos, então, uma figura de grande fôlego literário e vital, que assume desde o início a importância de um mito e de um colosso. A importância de um heterónimo.

No dia em que saiu Tiago Veiga. Uma Biografia (2011), o poeta já não era, ao contrário do tempo da notícia da sua morte (1988), um 
completo estranho e desconhecido. Entre 1988 e 2011, Mário Cláudio fez publicar 3 obras de Veiga: Os Sonetos Italianos de Tiago Veiga (2005), Gondelimde Tiago Veiga (2008) e Do Espelho de Vénus (2010), publicando, posteriormente, em 2016, a obra Dezassete Sonetos Eróticos e Fesceninos.

Tiago Veiga. Uma Biografia é uma obra na qual o biógrafo, de forma sólida e definitiva, institui o poeta minhoto como uma referência no panorama literário e cultural português. A Biografia surge, então, como género literário capaz de servir de documento de autenticação ou argumento de autoridade capaz de provar a real existência de Veiga para lá da verdade de papel. O nome próprio e a escrita literária única são também marcas evidentes da sua natureza heteronímica, ainda que diferentes daquelas que Pessoa tecera.

Um outro mecanismo adotado por Mário Cláudio e que, por sua vez, Pessoa não conseguiu levar a bom porto, ${ }^{1}$ foi o facto de o romancista nunca negar a existência física de Veiga, assim como nunca o considerar um heterónimo.

Após a publicação da Biografia, José Carlos de Vasconcelos e Maria Leonor Nunes, em entrevista do $J L$ ao escritor, formulam a seguinte questão: "Neste caso é que o autor pode dizer, como Flaubert de Madame Bovary, "Tiago Veiga c'estmoi»??" (CLÁUDIO, 2011, p. 7), Mário Cláudio prontamente responde: "Não posso, porque Tiago Veiga não sou eu (...). Tenho uma personalidade mais afável do que ele. Mas qualquer biografado é muito contaminado pela personalidade do seu biógrafo" (CLÁUDIO, 2011, p. 7). Mais à frente, os jornalistas tentam nova invetiva ao perguntarem, agora de forma mais direta e contundente: "Continua portanto a dizer que Tiago Veiga não é um seu heterónimo?" (CLÁUDIO, 2011, p. 7).

A resposta de Mário Cláudio é reveladora em várias sentidos, como veremos, uma vez que abre o caminho para um novo processo

\footnotetext{
${ }^{1}$ Ainda que o poeta tenha levado a teoria do fingimento demasiado a sério, querendo publicar a obra de Caeiro, Reis e Campos de forma autónoma e independente, não o fez, pois a sua ideia de dar a entender que Caeiro, por exemplo, existe de facto, se esmorece. É o que podemos ler numa carta que endereça a João Gaspar Simões, de 3 de março de 1932: "Não sei se alguma vez lhe disse que os heterónimos (segundo a última intenção que formei a respeito deles) devem ser por mim publicados sob o meu próprio nome (já é tarde, e portanto, absurdo, para o disfarce absoluto)" (PESSOA, 1999, p. 270).
} 
de criação heteronímica, ainda que sob um manto aparentemente contraditório e paradoxal: ao negar a não existência de Veiga, Cláudio instaura a sua realidade física, por um lado, através da sua extensa biografia e contactos que manteve com inúmeras pessoas, surgindo, assim, o relato como protocolo de acreditação; por outro lado, ao não afirmar que Veiga é um heterónimo, o biógrafo adensa o mistério em torno da personagem, levando, assim, a heteronímia a um novo limite, ou, por outras palavras, a quebrar a barreira da realidade-ficção, já que o propósito último da heteronímia será, portanto, não sabermos ao certo e verdadeiramente se Tiago Veiga existiu, de facto, enquanto pessoa real.

A resposta de Mário Cláudio levar-nos-á ainda a um outro caminho que será trilhado por Veiga: o facto da contemporaneidade dos heterónimos em relação ao ortónimo:

Para ser um heterónimo meu teria que manter comigo um certo umbicalismo. Se pensarmos no grande exemplo da heteronímia em Portugal, os heterónimos pessoanos, verificamos que todos eles são mais ou menos contemporâneos do ortónimo. Se Tiago Veiga fosse meu heterónimo, e digo francamente que não é, não poderia tê-lo inventado a fabricar, muito antes de eu ter nascido, coisas que eu próprio fabricaria...(CLÁUDIO, 2011, p. 7).

É, assim, sobre mais esta premissa que Mário Cláudio adensa a teoria da heteronímia. Para além da fragmentação do próprio heterónimo em diversas personalidades literárias, o escritor afirma constantemente a existência real do poeta, referindo-se, ainda, ao facto de ambos não serem contemporâneos. Veiga nasce em 1900 e Mário Cláudio em 1941.

Como já podemos ver, o caminho que leva à heteronímia em Tiago Veiga não parece tão linear quanto aquele que Fernando Pessoa utilizou para a criação de Alberto Caeiro, Ricardo Reis e Álvaro de Campos. Com a mudança dos tempos e a evolução dos paradigmas estéticoliterários, de realçar a agudização da crise ontológica e epistemológica, os preceitos que Mário Cláudio utilizará para dar corpo a Veiga necessitam, inevitavelmente, de outras fontes e outros caminhos.

Miguel Real, num texto escrito para o $J L$, afirma que Tiago Veiga é o "quarto heterónimo", uma vez que, se em 1942 Adolfo Casais Monteiro deu a conhecer a carta sobre a génese dos heterónimos, "2011 ficará na história da Literatura Portuguesa como o ano de criação de um quarto heterónimo" (2011, p. 10). 
Nesta sua crónica, o ensaísta recupera uma certa arqueologia da história da heteronímia na literatura portuguesa, ao referir Carlos Reis e o seu artigo sobre o projeto heteronímico em Fradique Mendes (Vide REIS, 1984). De facto, são estas as duas únicas referências que encontramos acerca da história e do percurso da heteronímia nas letras portuguesas.

Na génese da criação de Tiago Veiga está um caminho diferente daquele que foi delineado por Pessoa, diz Real. Já não basta "uma página a enunciar datas de nascimento e morte, terra de naturalidade, profissão, vocação literária, etc., como fez Pessoa" (Real, 2011, p. 10). Agora é necessário ser mais rebuscado, indo, assim, beber ao

\begin{abstract}
império da imagem - prestar consistência ao heterónimo através de um álbum de fotografias (...). E, no tempo do império das relações sociais, é forçoso prender o heterónimo a uma rede de conhecimento de nomes públicos que, a fortiori, preste consistência à sua existência (...). E assim criou Mário Cláudio o "mito" Tiago Veiga, recriando uma nova teoria da heteronímia, que deverá ser obrigatoriamente tida em conta na história da literatura portuguesa do século XXI (Real, 2011, p. 10).
\end{abstract}

Deste modo, Miguel Real apresenta duas novas características sine qua non para a nova teoria da heteronímia: a necessidade da imagem enquanto prova documental e palpável e a criação de uma rede social alargada onde estejam presentes nomes conhecidos e com provas dadas no domínio público, político, cultural e intelectual.

Como já referimos anteriormente, acreditamos ser possível ainda acrescentar umas outras tantas ${ }^{2}$ à proposta de Real. São elas, agora esquematizadas e organizadas:

Características propostas por Fernando Pessoa: 1) Nome próprio; 2) Biografia alternativa; 3) Escrita literária única.

Características propostas por Miguel Real: 1) fotografias, imagens que comprovem a real existência do heterónimo; 2) rede social onde constem nomes conhecidos.

Característica por nóssugerida: 1) necessidade de estar em constante movimento, em viagem.

\footnotetext{
${ }^{2}$ De salientar que este texto é fruto da nossa investigação e da tese de doutoramento, sendo que outras características surgem para a nova criação heteronímica, a saber: 1) Fragmentação do heterónimo noutras personalidades; 2) realizações intermediais do heterónimo (escrita, pintura, entrevistas, áudio); 2.1) reflexões ecfrásticas.
} 
Desta feita, acreditamos ser possível analisar Tiago Veiga a partir de todos estes preceitos, uma vez que é nosso propósito comprovar os aspetos que já fomos apresentando ao longo da reflexão, como também aqueles que agora surgem por imposição das circunstâncias. Todas eles parecem complementar-se, dando a entender a mudança dos tempos e a cada vez maior cisão da unidade do sujeito.

Primeiramente, as características teorizadas por Fernando Pessoa são óbvias e indispensáveis. Não faz sentido falar em heterónimos ou heteronímia sem falar no autor de Mensagem. Em segundo lugar, as apresentadas e propostas por Real são também evidentes em Tiago Veiga. Uma Biografia. Basta visitarmos os dois suplementos repletos de fotografias de Veiga enquanto jovem, adulto e em idade avançada, fotos ainda das suas tias e da casa dos Anjos, mas também as fotos de personalidades com as quais travou conhecimento. No "império da imagem", de facto, as fotografias parecem substituir toda e qualquer palavra. No entanto, se é certo que a necessidade das imagens é inevitável para justificar os pontos propostos por Real, não é menos certo afirmar que a biografia em si, enquanto documento com mais de setecentas páginas, acaba por ser o mármore no qual Mário Cláudio cinzela a existência de Tiago Veiga. Não é por acaso que, numa outra entrevista dada em 2011, o biógrafo fala da necessidade e da importância da biografia, não como artefacto histórico e como preceito de verdade científica, mas antes como necessidade da ficção, de modo a entendermos quem foram, de facto, aquelas criaturas, quais os seus desejos e as suas ambições, não somente através dos seus escritos, mas também por via da sua vivência interior. Quando Rui Lagartinho pergunta "porque inventa e não desinventa, podemos concluir que de facto Tiago Veiga nunca pode ser visto como um heterónimo do biógrafo Mário Cláudio...", o romancista responde:

Os heterónimos são essa tal desinvenção. Veja-se o caso de Fernando Pessoa com as mini biografias que criou para os seus heterónimos. São esquemáticas e não nos permitem saber nada sobre a forma como eles funcionavam por dentro. Quem eram as mulheres da vida de Ricardo Reis, ou os homens da vida de Álvaro de Campos? Sabemos apenas algo, pouco, sobre a sua diversa orientação sexual. Eu não quis estilizar a vida de Tiago Veiga. Qualquer pessoa é o que ela pensa, o que ela imagina, a sua atmosfera, o ar que respira, em que vive. A sua aura. Tiago Veiga é uma figura de carne e osso. Não é um heterónimo. Quem tiver dúvidas pesquise, que vá aos cartórios.(LAGARTINHO, 2011) 
Surge agora o momento de entrarmos em Tiago Veiga. Uma Biografia, de modo a entendermos como se dá esta nova criação heteronímica a partir da necessidade da viagem e de estar em constante movimento.

Tiago Veiga é um homem múltiplo, filho do seu tempo e de uma longa herança que nasce com o advento daquele que seria o Movimento das grandes paisagens e da subjetividade.

Porém, é com a chegada do Modernismo, ou dos modernismos, que as verdades estabelecidas se rompem e começam a ser relativizadas. A modernidade da vanguarda e os gritos iconoclastas que ecoavam pela Europa e América tinham em si tanto de revolucionário como de paradoxal. Se ao mesmo tempo o homem cantava o momento presente, a glória do desenvolvimento tecnológico e industrial que levaria à inevitável felicidade humana por via do progresso, por outro lado, a guerra e as sucessivas crises políticas e económicas abalaram essa crença na Ciência, levando o sujeito a ver a sua identidade, que se pretendia una e harmoniosa, dispersa, diluída e fragmentada. Os valores que regiam o mundo são agora relativizados e o sentido da vida tornou-se qualquer coisa distante. Com o passar dos tempos, todos estes sintomas serão agudizados e intensificados, sendo que o Post-Modernismo levará a um outro patamar a crise do estilhaçamento do sujeito, não só através da deslegitimação dos "códigos genológicos e periodológicos" (ARNAUT, 2010, p. 131), mas também a partir da liquidez dos tempos, como afirma Zygmunt Bauman.

Segundo o sociólogo polaco, "a pedra de toque da estratégia de vida pós-moderna não é a construção da identidade, mas a prevenção da fixação" (BAUMAN, 2007, p. 95).

O nosso mundo torna-se, então, num mundo líquido, o que de acordo com Michel Maffesoli e Zygmunt Bauman tem que ver com a fluidez da vida moderna que, devido à “"«perte d'auréole» (Baudelaire) du monde moderne est due à la perte de la solidité grâce à laquelle on avait ja dis l'impression d'une securité immobile" (MAFFESOLI, 2014, p. 17). O sujeito moderno passa, pois, a ser o "Homo fractilis" (MAFFESOLI, 2014, p. 36) e o "Homo erraticus" (MAFFESOLI, 2014, p. 169).

Tiago Veiga insere-se nesta imagem do homem que viaja e que está em constante movimento, pois ao longo da sua extensa biografia, várias são as viagens que realiza não só pela velha Europa (Inglaterra, Itália, França, Irlanda, Espanha, Países Baixos e Israel), mas também 
pelo continente africano (Guiné-Bissau e Marrocos) e americano, pelos Estados Unidos da América.

Veiga nasceu no Brasil, sendo filho de dois europeus que emigraram para esse país nos finais do século XIX, o que acaba por criar uma auréola de eterno viajante em seu redor.

Logo nos seus primeiros anos, aquando da sua passagem pelo Seminário de Braga, Tiagoe os seus colegas não tinham poiso certo, visto que

Não existindo internato, andavam os meninos de Paredes de Coura, e bem assim os restantes dezanove que com eles se iniciavam nos enredos teológicos, em verdadeiras bolandas, ora pernoitando em aposentos alugados, ora hospedados pelas famílias de boa vontade da terra, incertos de poiso no dia seguinte. (CLÁUDIO, 2011, p. 69).

Esta passagem demonstra que Tiago Veiga tem, desde tenra idade, uma vida assente na deambulação, na constante mudança e no movimento.

Tal comos os turistas, que não têm lugar certo, mas têm sempre um local ao qual podem chamar "casa", o mesmo acontece com o "nosso homem". A Casa dos Anjos, apesar das várias e variadas viagens, acaba por ser o local onde Veiga retorna, o "seu refúgio" (CLAUDIO, 2011, p. 494).

Quando chega a Londres, pelo Verão de 1918, para ir estudar arquitetura naval no Royal Naval College, curso que jamais terminaria - 0 que é apanágio deste homem que nunca se prende a nada ou a ninguém - Veiga tem muito tempo livre, tempo esse que será a oportunidade "da deambulação, e só da deambulação" (CLAUDIO, 2011, p. 124).

Em Londres, e com pouco mais de 20 anos, Veiga irá escrever o seguinte a Alvaro Guevara, pintor chileno que conhecera na capital britânica graças aos seus contactos em torno de LadyOttolineMorrel:

«Bebi mais nevoeiro lá em baixo do quanto poderia ter emborcado nesta cidade, há um tempo para tudo, e o meu por aqui já se esgotou, vou a Paris, é provável que volte, e é provável que não, de momento pretendo esquecer, mas não entendo bem o quê» (CLAUDIO, 2011, p. 141). 
Esta propensão da viagem e da constante deambulação de Tiago Veiga torna-se condição necessária para a sua caracterização heteronímica, na medida em que a sua complexidade humana e densidade psicológica se vão revelando em cada uma das suas paragens nos diversos locais. A duração da estadia em qualquer lugar não chega a ser devidamente planeada com antecipação, uma vez que a ordem harmoniosa do mundo, e do sujeito, desapareceu. O mesmo acontece com o destino seguinte. A peculiaridade da vida dos que vagueiam, e dos turistas, é, portanto, "estar em movimento, não chegar" (BAUMAN, 1991, p. 114).

O turista que Tiago Veiga é descende de uma linha que começa com as Grands Toursdo século XVIII, sendo Goethe o seu exemplar máximo. Contudo, existem mudanças que nos dizem muito sobre o viajante, e, neste caso, sobre o turista e o vagabundo que é o vate minhoto.

No tempo de Goethe, o homem de letras, ao mesmo tempo que devia ser cosmopolita e encetar a Grand Tour, ${ }^{3}$ viagem de autoconhecimento $\mathrm{o}^{4}$ de aprofundamento dos saberes relacionados com as grandes civilizações antigas, deveria ser votado ao celibato e ter como interesse supremo o conhecimento não para usufruto próprio e oportunista, mas sim em nome da humanidade e da razão como fonte de progresso e desenvolvimento da sociedade.

No tempo de Tiago Veiga, a viagem assume um outro propósito que não somente o do autoconhecimento. Por outras palavras, a viagem surge como necessidade de estar em movimento, de não se prender a lugar algum, uma vez que a busca de significado parece para sempre perdida, pois a solidez de todas as coisas esvaiu-se com a rapidez do mundo, da tecnologia e das relações humanas. Estar em movimento, "antes um privilégio e uma conquista, torna-se uma necessidade" (BAUMAN, 2006, p. 15).

\footnotetext{
${ }^{3}$ A referência máxima da Grand Tour era a Itália. Viajar tornara-se, de facto, a partir de meados do século XVIII, numa arte e numa espécie de jogo para o qual o viajante se devia preparar.

4 "Verona, 17 de Setembro de 1786 - Não faço esta bela viagem para me iludir a mim próprio, mas para me conhecer melhor a partir dos objetos que contemplo (...). Nápoles, 26 de Março de 1787 - As dúvidas sobre se deveria fazer a viagem ou ficar trouxeram uma certa inquietação (...). Para uma natureza como a minha esta viagem é benéfica, mesmo necessária. (...) Nesta viagem aprendo certamente a viajar; se aprendo a viver, isso não sei”. (GOETHE, 2001, p. 33 e 273-275, respetivamente).
} 
É em Paris, cidade da boémia, dos turistas e dos flâneurs por excelência, que nos deparamos com um Tiago Veiga assumidamente deambulador e turista da modernidade e post-modernidade:

Subia e descia a rueMontCenis, ou ascendia à PlaceduTertre, irritando-se por se achar na pele de mais um touriste, lançando o olhar guloso a cada porta entreaberta, ou deliciando-se com o presumível pintor que carregava o cavalete às costas, duas telas nuas debaixo de um braço, e a caixa das tintas debaixo do outro. (...) Não era porém dentro de si mesmo que se reconhecia, mas no corpo de um adventício ridículo, coleccionador de bilhetespostais, e sem poder de compra (...). Vezes sem conta perguntarse-ia, «O que faço eu aqui?», colhendo a resposta única em ocasiões similares, a que, não satisfazendo qualquer interrogação, todavia, aponta em seu silêncio para aquela espécie de mosaico rigorosíssimo que o percurso de todos nós, ainda que visitado pela ventania do caos, ou pelas trevas da depressão, acaba por compor (...). E nessas duas iniciais semanas parisienses, aborrecido de leituras e escritas, dormia Tiago Veiga sob o pasmo que o ia dominando, arrepiando-se com o dobre dos sinos do Sacré-Coeur, o que afinal se lhe afigurava destino razoavelmente romanesco (BAUMAN, 2006, p. 160).

O turista viajava, não por necessidade, mas antes por um impulso exterior em busca de alguma coisa fora do seu lugar de conforto, uma vez que no meio da multidão e das grandes cidades são as impressões breves que interessam. $\mathrm{O}$ vagabundo, por seu turno, move-se por necessidade, uma vez que a nenhum lugar ele pertence ou tem que possa chamar casa.

Antes de prosseguirmos com a ideia do vagabundo, convém referirmos que o antecessor do turista e do vagabundo era o peregrino.

O peregrino, ao contrário daqueles dois, acreditava na solidez do mundo e nos grandes propósitos. $\mathrm{O}$ caminho e a viagem para $\mathrm{o}$ peregrino eram em si momentos de grande contacto com o mundo e com a sensibilidade interior. Não interessava somente chegar a um certo lugar, pois o caminho que se percorria era tão enriquecedor e importante quanto o destino. Mais do que caminhar ou andar, os peregrinos andavam para, isto é, caminhavam acreditando num destino, num sentido último. O destino, "o fim declarado da peregrinação da vida, dá uma forma ao que não a tem, torna o fragmentário totalidade, confere continuidade ao episódico" (BAUMAN, 2007, p. 92). 
O problema da identidade do sujeito parece não estar na sua construção, mas sim no encontrar uma forma de a manter. No nosso mundo líquido e fragmentado, o que acontece é que as identidades podem ser adotadas e depois postas de parte, com a facilidade de quem muda de roupa. É aqui que turistas e vagabundos surgem como os sucessores do peregrino.

Para o vagabundo,

estar livre significa não ter de viajar de um lado para o outro. Ter um lar e ser permitido ficar dentro dele. São esses os vagabundos, luas escuras que refletem o brilho de sóis brilhantes, os mutantes da evolução pós-moderna, os refugos inaptos da brava espécie nova (BAUMAN, 1991, p. 117).

Se o turista tinha um lugar ao qual pudesse regressar após as suas bolandas, o vagabundo tem o seu lar em todo o lado e em parte alguma, uma vez que tem em si todos os perfumes e as experiências de todas as viagens e deambulações.

Todavia, restam somente os fragmentos de todas essas experiências, uma vez que o móbil último seria a busca de uma identidade una e harmoniosa. O que acontece é que a busca e a deambulação acabam por ser um granítico e sisífico caminho, uma vez que o caminho do vagabundo é agora cruzado por muitos outros vagabundos. O caminho em busca de um sentido último para a vida, na descoberta da identidade é um enigma constante, já que parece estar vedado ao sujeito da modernidade líquida o acesso a essa verdade que, parece-nos, jamais chegou a existir verdadeiramente.

Lembrarmo-nos de um passado e de tudo o que ele tinha é, portanto, saber aquilo que não temos hoje. Tiago Veiga é também um vagabundo, uma vez que em lugar algum encontra poiso certo, mesmo até em Venade, na sua Casa dos Anjos. A deambulação deixa de ser um rito iniciático e torna-se num contrafeito, mas inevitável modus vivendi:

E também ele, o nosso biografado, transitava por ali, cavaleiro Vagueante na jornada sem bússola, e tal e qual como saíra do Brasil e Coura, e deambulara depois por Braga, e por Lisboa, pela Itália, e por Paris, por Londres, e pela Guiné, pelo Porto, pelo Caramulo, e por Dublin. De semelhante maneira se encantara de uma mulher, se apaixonara por outra, e se inclinara para uma terceira, e lhe nascera uma filha, e um filho, e dialogara com este, e mais com aquele, e lera isto, e mais aquilo, e teimara em escrever a 
sua poesia, sempre motivado por sugestões vagas, e por pequenos achados, tangenciais à vida, tudo como se prosseguisse em busca da alma infinita que o habitava, e cujo murmúrio tragicamente desentendia. Aproveitando uma aberta nas persistentes chuvadas irlandesas, despediu-se Veiga (...), rumando de volta a Portugal (CLÁUDIO, 2011, p. 373-374).

Já com oitenta anos, Tiago Veiga surge a deambular pelas ruas da noite lisboeta, pelos bairros de Alfama e do Bairro Alto, em rusgas regadas de vinho, fado e navalhadas, demonstrando, até ao fim da sua vida, essa propensão à viagem e ao movimento, ainda que com laivos de misantropia e de um comportamento a roçar o ridículo e o infantil - não esqueçamos que os seres humanos são assim mesmo, temperamentais, sensíveis, falíveis e deliciosamente mortais.

Notamos que, ao longo da sua vida, Tiago Veiga adota uma postura que é muito semelhante àquela do Álvaro de Campos da sua fase intimista, pois ambos parecem enquadrar-se naquele sujeito que é o homem sem qualidades:

O mundo é para quem nasce para o conquistar

E não para quem sonha que pode conquistá-lo, ainda que tenha razão. (...)

Mas sou, e talvez serei sempre, o da mansarda,

Ainda que não more nela;

Serei sempre o que não nasceu para isso;

Serei sempre só o que tinha qualidades (PESSOA, 2013, p. 136).

Assim, "turistas e vagabundos são as metáforas em nossa sociedade pós-moderna, estamos todos - de uma forma ou outra, no corpo ou no espírito, aqui e agora ou no futuro antecipado, de bom ou de mau grado - em movimento" (BAUMAN, 1991, p. 118).

Tiago Veiga é o que vem depois do século XX. É o agudizar dessa crise da unidade do sujeito, é o filho de um tempo caótico e paradoxal. A crise da publicação e do público em Veiga advém de um esteio que passa por Campos e remota aos vates do Romantismo primeiro.

Sendo Álvaro de Campos o século XX corporizado por conta de todas as suas contradições entre o cosmopolitismo e a angústia de viver em inatividade em Lisboa, cantando o progresso e a civilização para, num momento posterior, soluçar pelas paredes húmidas o tempo da sua infância perdida, longe do movimento ambulatório das fábricas e das máquinas, Tiago Veiga é, sem sombra de dúvida, o seu direto sucessor espiritual, o seu filho nado e criado. 
Não falamos aqui dos temas da sua escrita, mas sim do modo de encarar a vida, ainda que sob uma faceta lunar. Se os românticos e os modernos querem causar espanto e admiração, Veiga não o deixa de fazer, mas invertendo esses papéis, tornando-se discreto, fugaz, ao jeito de Pessoa. Se os românticos e os modernistas pretendiam criar uma nova arte, quebrar a tradição e o passado de modo a atingirem uma nova originalidade, Veiga, por seu turno, esquece o passado transformando-o, recuperando-o.

Tiago Veiga é o sucessor de Campos até na sua forma última de ver a vida: falhando em tudo, desistindo de viver. Durando. É na sua desistência da vida e do mundo, através da tentação do lume e do seu suicídio, que Veiga se liberta e se afirma como um novo paradigma de heterónimo, de personagem e de escritor: ultrapassando os limites de Pessoa, rompendo as convenções da ordem criador-criatura, ultrapassando as leis da ficção, pedindo a Mário Cláudio a realização da sua biografia, recorrendo à imaginação e à fantasia, recusando, assim, os embustes românticos de manuscritos encontrados, negando e criticando, ainda, as ridículas tentativas de tornar a escrita literária num processo equiparável a um método científico.

Veiga é um cético e um pessimista, sendo os seus últimos anos, ainda que por vezes reanimados por súbitas vontades de escrita, votados à angústia e à desolação, sendo um filho de Álvaro de Campos pessoal e intimista, como já verificámos, não crendo em nada, falhando em tudo. A desolação evidente nas palavras de Veiga reflete uma vez mais a total perda de uma suposta unidade que nunca esteve presente. Nas suas inúmeras viagens e relações com diversas pessoas de muitas origens e culturas, o poeta minhoto apercebe-se da perenidade da vida, da inexorável passagem do tempo e da certeza inevitável da morte, daí afirmar:

«Não acredito em mudanças, sejam elas de dono, de guia, ou de deus, porque não existe invenção que nos justifique a passagem pelo mundo, nem progresso que elimine miséria, desolação e morte.» (CLÁUDIO, 2011, p. 548).

O código genético-literário de Veiga advém dos grandes movimentos e da grande Literatura. A necessidade da viagem e de estar em constante movimento é, portanto, uma razão a fortiori para a sua existência, sendo uma característica fundamental a acrescentar à teoria da heteronímia pessoana. 
Já não é suficiente inventar um nome, uma biografia e um estilo diferente, agora é necessário revestir e avolumar o interior do heterónimo, surgindo a viagem e a necessidade e estar em deambulação como forma última de o heterónimo expressar toda a sua complexidade humana e densidade psicológica. Ao mesmo tempo que é realçada a importância da identidade e da crise da unidade do sujeito, sobressai-se a humanização efetiva de Veiga, a partir das suas escolhas, dos seus silêncios, das suas virtudes e dos seus defeitos.

Todas as viagens encetadas pelo "Esfinge Magra" não deixam de ser a metáfora do homem moderno em busca de si próprio, num espaço sempre distante e alheio, refletindo, assim, a fuga de si próprio, numa sintomática falência das verdades até então aceites. Se a verdade está sempre alhures é necessário procurá-la. Todavia, na busca que é feita, o caminho não é em si tido em consideração, isto é, não se vê a travessia como ritual de autoconhecimento, importando somente a meta.

No entanto, chegado à meta, o sujeito parte novamente para outro destino em busca de um objetivo que nunca chega a alcançar, alienando e negligenciando a deambulação, que não passa de uma mera necessidade. O sentido que se pode obter do caminho acaba por ser uma forma de criar um sentido outro, capaz de ir ao encontro das expetativas do sujeito, e neste caso, de Tiago Veiga.

Assim, a liquidez dos tempos atuais não permite nem perdoa a capacidade de abrandar o ritmo da procura e da busca de um sentido, daí o poeta minhoto surgir em constantes viagens, em busca de qualquer coisa que não sabe muito bem ao certo o que possa ser.

O que aqui fica proposto é uma leitura, uma aproximação outra à teoria da heteronímia, daí que este não seja $O$ Tiago Veiga, mas sim Um Tiago Veiga líquido, possível entre outros tantos, perdidos no anonimato da grande vida moderna, comum transeunte de um lugar que será sempre aquele vaticinado pelo engenheiro naval: o da mansarda.

\section{Referências}

ARNAUT, A.P. Post-Modernismo: o futuro do passado no romance português contemporâneo.Via Atlântica, n. 17, jun. 2010.

BAUDELAIRE, C. O Pintor da Vida Moderna. 6. ed. Tradução de Teresa Cruz. Lisboa: Nova Vega, 2013. 
BAUMAN, Z. Amor Líquido. Tradução de Carlos Alberto Medeiros. Lisboa: Relógio D’Água, 2006.

BAUMAN, Z.A Vida Fragmentada. Ensaios sobre a Moral Pós-Moderna. Tradução de Miguel Serras Pereira. Lisboa: Relógio D’Água, 2007.

BAUMAN, Z.O mal-estar da Pós-Modernidade. Tradução de Mauro Gama e Cláudia Martinelli Gama. Rio de Janeiro: Jorge Zahar Editor, 1991.

CLÁUDIO, M. Tiago Veiga. Jornal Tempo, 18 ago. 1988.

CLÁUDIO, M. Tiago Veiga. Uma Biografia. Lisboa: Dom Quixote, 2011.

GARDEAZABAL, J. Dicionário de Ideias Feitas em Literatura. Lisboa: Relógio D’Água, 2016.

GOETHE, W. V. Viagem a Itália. Tradução, Prefácio e Notas de João Barrento. Lisboa: Relógio D’Água, 2001.

FLAUBERT, G. Dicionário das Ideias Feitas. 2.ed. Tradução de João da Fonseca Amaral. Lisboa: Editorial Estampa, 1990.

LAGARTINHO, R. "Sou incapaz de desinventar completamente uma vida." Entrevista a Mário Cláudio. Disponível em: $<$ https://www.publico. pt/2011/06/29/culturaipsilon/noticia/quotsou-incapaz-de-desinventarcompletamente-uma-vidaquot-288369>. Acesso em: 8 jan. 2018.

PESSOA, F. Correspondência. 1923-1935. Edição de Manuela Parreira da Silva. Lisboa: Assírio e Alvim, 1999.

PESSOA, Fernando. Poesia de Álvaro de Campos. Lisboa: Assírio e Alvim, 2013.

REAL, M. Nova Teoria da Heteronímia.JL, n. 1062, 15 a 28 jun. 2011.

REIS, C. Fradique Mendes: Origem e modernidade de um projecto heteronímico.In: ROCHA, A. C. (Dir.).Cadernos de Literatura. Coimbra: Centro de Literatura Portuguesa, 1984. v. 18.

SHIN, J. Le flâneur postmoderne. Entre solitude etêtre-ensemble. Paris: CNRS Éditions, 2014.

VASCONCELOS, J. C. de V.; NUNES, M. L. Mário Cláudio. Uma “vida" de Tiago Veiga.In: $J L$, n. 1062, 15 a 28 jun. 2011. 